\title{
Managing Internships: Experiential Learning That Can Benefit Business Students, Industry, And Academic Units
}

Mary Ann Boose, (Email:isboose@ befac.indstate.edu), Indiana State University

\begin{abstract}
This study examines the practices and procedures of three internship programs, and communicates the findings of the programs concerning the benefits to students, businesses, and academic institutions. Although the internship programs examined in this study vary considerably, the common element is the early connection of students to employers and careers.
\end{abstract}

\section{Introduction}

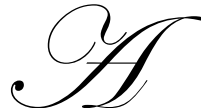

lthough many sources supply the latest basic, applied, and pedagogical research in business fields, no research has been conducted concerning the tools, techniques and programs that constitute the best practices in co-curricular or extra-curricular support for our students. Rabel's (1992) working draft of a manual on managing an effective university program in risk management and insurance is that discipline's only resource. It focuses "on those activities that seem to be essential to the success of most programs so that they can survive and thrive and allow teaching and research to take place." However, it is primarily an enumeration of ideas designed to help professors to "enhance their chances for success by ensuring that their programs are demanded by students, and respected and supported by constituencies inside and outside the university."

Rabel encourages professors to "aggressively manage the 'non-academic' aspects of their programs in a variety of ways, including: recruiting students, maintaining support at the institutional level, fostering support from the business community, and engendering alumni loyalty and participation." In short, Rabel created what he called a "menu of ideas ... which appear to have a reasonable hope for success." Unfortunately, Rabel's work contains no details or prescription for successful implementation of these ideas. Extension of this work by recording the current state of business education, and by careful documentation of the procedures for implementing and managing best practices is both timely and essential to the discipline. One of the ideas on the menu is internships, which Rabel proposes as one of his suggestions for providing a stimulating program, and which he views as a part of the successful placement of students.

In apparent agreement with Rabel, professors surveyed by Ferguson et. al. (2000) believe that internships are important to their students. Ferguson reports that $80 \%$ of surveyed professors agree or strongly agree that their students "actively seek internship opportunities." Further, over $60 \%$ of the professors agree or strongly agree that "internships offer potentially valuable learning opportunities and should be required of all their majors" (emphasis added). Interestingly, of the 24 responding programs surveyed (Boose, 2001), $75 \%$ (18 programs) reported that their students were involved in internships during the prior 12 months. Unfortunately half of those institutions reported fewer than ten students in such positions, leaving only twelve programs with eleven or more interns.

This article discusses the common elements of highly effective internship programs that are sponsored by programs at three AACSB accredited schools of business. Among these three are a diversity of program sizes, 
institutional support, procedures, and practices. The common element is the effective and early connection of students to careers. Professors will be able to use the results of this study to implement internship programs on their campuses for the benefit of their own students and the industry in their region.

\section{Definition Of An Internship}

An internship is a form of experiential learning that includes part-time or full-time employment under the guidance and direction of a sponsoring organization. For aspiring professionals, an internship is an opportunity to make the learning process more relevant by coordinating classroom theories with practical experience which may help the student/intern to make critical career decisions. Further, it gives the sponsoring organization the opportunity to evaluate the intern pro possible future employment.

The three cooperating entities in an internship are the student, the sponsoring organization, and the university, usually represented by the school of business or the specific academic department or program. All three of these partners in the internship share the challenge of nurturing the intern's professional growth. Further, each stands to benefit from this drawing together of disparage elements into a new and potentially satisfying work relationship.

\section{Advantages}

Internships provide the opportunity for students, the industry, and the academic program to engage in an endeavor that provides benefit to all three entities, an outcome that Ferguson (2000) refers to as a win-win-win proposition.

\section{Advantages to Students}

For aspiring professionals, an internship is an opportunity to make the learning process more relevant by coordinating classroom theories with practical experience which may help the student make critical decisions concerning his/her future career. Specific benefits include:

- $\quad$ connection to the industry and professional networking opportunities,

- $\quad$ professional growth and development,

- the acquisition of information concerning potential career fields,

- the ability to compare personal traits and interests to those necessary for success in the field chosen for the internship,

- the opportunity to acquire real-world experience without making a commitment to permanent employment,

- the opportunity to form a relationship that may yield a full-time career,

- the opportunity to receive academic course credit for applied education in the industry, and

- the economic benefit of working for wages that typically exceed those available to student workers.

Interestingly, concerning the educational advantage of internships, Hite and Bellizzi (1986) found that internships provided a more valuable learning experience than case courses or a series of guest lectures in class.

In addition to these advantages, a survey of intern and non-intern business alumni of a northeastern US public university (Gault, 2000) indicated significant early career advantages for undergraduates with internship experience. The advantages they found included :

- $\quad$ less time to obtain first position,

- $\quad$ increased monetary compensation, and

- $\quad$ greater overall job satisfaction. 


\section{Advantages To Industry Sponsors}

Although formerly perceived as a donation to the university and the student involved, increasingly intern sponsoring organizations are indicating that they receive tangible returns from their participation in internships. Most frequently cited benefits to the sponsoring organizations include the opportunity to:

- $\quad$ provide students with a job experience that closely relates to the actual career(s) available to entering college graduates,

- $\quad$ provide students with a realistic view of the industry,

- $\quad$ form relationships with potential future employees,

- $\quad$ reduce the cost-per-hire of recruiting new employees (Gault, 2000),

- recruit and train potential future employees, enriching the pool from which to draw prospective workers,

- observe and evaluate prospective employees over an extended period of time, prior to making the commitment to hire,

- $\quad$ enhance the reputation, on campus, of the particular organization, and

- network with the intern's peer group at the university.

In addition to these opportunities, most sponsoring organizations indicate that the intern accomplished a significant quantity of work that would otherwise have gone undone (in the case of special projects) or have caused an overload to regular staff (especially in light of summer vacations or other staffing considerations).

\section{Advantages To The Academic Program, School Of Business, And University}

The time and effort required of university professors and staff are clearly valuable, limited resources. The decision, therefore, to engage in an active internship program must be at least partly motivated by benefit to the educational institution and its units. Specific benefits to the academic department or program, and by extension to their school, college, and university, include:

- $\quad$ the creation of a new learning laboratory, an adjunct to the campus-based curriculum, in which students can apply abstract classroom concepts to real lifee situations,

- $\quad$ the enhancement of the program's reputation among students,

- the enhancement of the program's reputation with industry employers,

- $\quad$ increased awareness of faculty members of current practices, issues, and opportunities in the industry, and

- $\quad$ increased awareness among faculty concerning industry needs (Martz, 1999).

\section{Procedure For The Successful Implementation Of An Internship Program}

Whereas many colleges and universities have excellent career centers that manage a university-wide coop or internship program, many academic programs have elected to implement internship programs of their own. This section and the related appendices present a model that is easily replicable.

In order to establish an internship within an academic program, the program must be characterized by the following attributes:

- It has a strong student body interested in the industry and its career opportunities.

- It has a good relationship, or is willing to make the effort to create a good relationship with some of the industry organizations in its region.

- It has a professorate that values industry connectivity and networking.

- It has one or more professor and/or staff member able and willing to dedicate the time necessary to administer the internship program. 

attributes:

Useful, but not essential to the implementation of a successful internship program are the following

- $\quad$ The university allows course credit for successful internships.

- $\quad$ The course credit is a required or elective part of the student's curriculum.

- $\quad$ Support for faculty who head internship programs, or who are responsible for internship courses. This could include staff support for administrative details, and/or including the internship course in the faculty member's teaching load, or release time for the faculty member's efforts to head the internship program.

\section{Time Table}

Late in the fall semester, flyers are posted informing students that internships will be made available by organizations in the local or regional business community for the upcoming summer months. In addition to posting notices, announcements are made in classes and at meetings of student organizations. Students interested in being considered for the internships are requested to complete an application form (see Appendix A for an example) and to submit it with their resume to the program office by the indicated deadline

Concurrent with the solicitation of student applications, the program office mails Sponsoring Organization forms (see Appendix B for an example) to all organizations that sponsored internships in prior years and to all individuals that are qualified prospects for starting an internship relationship with the program. Although many human resource managers and hiring managers respond readily to these letters and/or e-mail messages, staff and/or faculty time is allocated for telephone solicitation in order to assure that the appropriate number and type of internships is forthcoming. Periodic review of applications as they are submitted and discussions with students help to identify special needs, allowing the professor or staff to pursue opportunities in specific geographic locations, careers, or types of organizations.

During February, faculty and/or staff meet with each intern candidate to further identify special interests and to inform each student of opportunities that are expected to exist that might be particularly appropriate to that student's skills and interests. This step is particularly important as most students are not fully aware of their own potential in specific career paths or in some types of organizations. Further, many students have a tendency to wish to remain in familiar surroundings and need to be informed concerning the advantages of stretching outside their comfort zone. In particular, students may need to leave their (relatively small) home towns, or the city where their university is located in order to work in a home or regional office located in a nearby metropolitan area.

In March, materials are forwarded to the organizations that have agreed to sponsor interns. The materials include information concerning the responsibilities of the organization, as outlined below, and contact information for the university staff member or professor. The package will include resumes for the students most likely to fit the needs of the sponsor. Each sponsor is encouraged to contact the students directly for interviews (phone or in person), but the organizations are advised that the program is willing to establish a visit day for the human resource professional or hiring manager (s) if the organization prefers to come to campus to interview. Arrangements for employment are made directly between the sponsoring organization and the student/intern.

Sponsors and students are asked to inform the program office as commitments are made. This enables the staff or faculty member to intervene in the case of a sponsoring organization or student that does not appear to have an adequate number of possible prospects.

\section{Responsibilities}

Each of the three parties to the internship program has its own responsibilities. The following section details the expectations from the student, the sponsoring organization, and the university staff and/or professor. 


\section{The Responsibilities Of The Sponsoring Organization}

Organizations providing internships should plan to provide full-time employment for 10 to 12 weeks beginning shortly after the close of the spring semester (mid-May). The intern's supervisor's contact information should be reported to the program's contact person.

The work assignment for the interns should be in keeping with their preparation for a career in the industry. Organizations are expected to specify the functional areas (investments, claims, underwriting, pensions, etc.) in which the interns will be employed. Many successful internships involve rotation through several functional areas in order to provide the intern with a variety of work experiences, a better understanding of the relationships among the various departments and the work for which they are responsible, and a broader knowledge of the organization as a whole. Many organizations assign responsibility for participation at training or developmental activities, for completion of industry or company training course materials. Many supervisors allow their interns to sit in on management or committee meetings which would normally not be open to new or lower-level employees. Organizations are strongly encouraged to have a written plan for the intern for the employment period.

At all times, on-site work supervision and guidance is provided by the supervisor/mentor chosen by the sponsoring organization. Selection of a highly skilled and motivated supervisor/mentor is essential to the success of an internship. Supervision of an intern is a time-consuming and difficult task because most students have not acquired the advanced knowledge and sophisticated skills necessary for most technical positions. It is preferable that the supervisor/mentor be at the middle level of management or higher. He or she should have a record of operational achievement, the demonstrated ability to develop subordinates, and a willingness to share time and experience with the intern.

Compensation provided by companies should be adequate for students to maintain a proper standard of living in the community where they are employed. In some locations, especially major metropolitan areas that are not "home" to the interns, sponsoring organizations assist with recommendations concerning short-term housing for interns. The compensation provided does not ordinarily include benefits.

During the course of the internship, the sponsoring organization should expect to host an on-site visit from the professor. This normally entails individual meetings with the intern, the supervisor, and any human resource professional involved in the coordination of the internship. As appropriate, team meetings may replace individual interviews.

At the end of the internship, an Intern Evaluation Form (see Appendix C) is sent to the organization to enable the supervisor and human resource manager to provide a written appraisal of the work of the intern and to make suggestions for improvement in the program. When the sponsoring organization has its own evaluation form that covers substantially similar questions performance ratings, and in when that organization is willing to share the information from its evaluation with the professor, it is not necessary to duplicate effort by completing the evaluation form.

\section{The Responsibilities of the Intern}

The intern should enter the internship opportunity with set personal, professional, and academic goals. The intern is expected to meet his or her responsibilities as agreed when offered the internship. This includes assigned work and hours as originally agreed. It further includes responsibility for behavior consistent with a regular employee of the sponsoring organization. The intern should expect to be subject to the same rules and procedures as other employees, including procedures concerning the time allocated for breaks, the use of company equipment including computers and communication equipment, and all expectations for timely and professional completion of all assigned tasks.

The intern will complete daily records (see Appendix D) and weekly reports (see Appendix E) and return them to the academic program office each week. This is required of each intern whether or not the student decides 
to enroll for course credit. Under most circumstances, with approval of the appropriate professor or academic unit, and assuming prior successful completion of any prerequisite course(s), interns will enroll for three semester hours of credit in the internship course. Students who enroll for credit are required to complete a written term project or paper. The tuition expense is borne by the intern unless there is prior agreement by the sponsor to pay or to reimburse the cost. This is true regardless of any benefit normally available to employees of the sponsoring organization. Most interns do not receive fringe benefits from their sponsoring organizations.

\section{The Responsibilities of the Academic Program}

The academic program is may choose to coordinate the solicitation of sponsorships and the selection of students for recommendation to each sponsor, or it may choose to simply post opportunities or to delegate responsibility for each of these tasks to the university's career and placement services office. Likewise, the program may choose to host university-based interviews, or to engage in other activities that facilitate communication between the students seeking internships and the industry organizations that sponsor internships.

Often, the academic program staff or faculty member responsible for the internship program will take a very active role in identifying the best fits between the students and sponsors. In these cases, the intern coordinator will make several judgmental decisions. First, he or she considers the requirements of each internship and appraises the student's ability to handle the work. The coordinator also assesses the degree to which a particular internship complements the student's previous experiences. In addition, before approving an assignment, he or she must gauge the fit between a particular student and the culture of the organization where the student wishes to intern. In short, the coordinator appraises the probability of success and assesses the potential for growth that a particular experience will afford the student/intern.

The faculty member responsible for the intern course is responsible for design of the syllabus, including grading criteria which may include timely submission of weekly reports, the evaluation of the supervisor in the sponsoring organization, and the term paper or project. The faculty member will visit the sponsoring organization and review the progress of the intern with the intern's supervisor during the period of employment.

\section{Conclusion}

Internships provide the opportunity for business students, industry, and academic programs to engage in an endeavor that provides benefit to all three entities. For aspiring business professionals, an internship is an opportunity to make the learning process more relevant by coordinating classroom theories with practical experience which may help the student make critical decisions concerning his/her future career. Employers have the opportunity to form relationships with potential future employees, to evaluate them prior to making the commitment to hire, and to network with the intern's peer group at the university. Finally, the academic program benefits from an enhanced reputation among the industry that supports it and among the students on their campus. This study examined the practices and procedures of internship programs on a diverse set of campuses. Although the internship programs examined in this study vary considerably, the common element is the early connection of students to employers and careers. Internships can provide excellent opportunities for our students, industry, and academic units to work together for the benefit of all parties.

This study extends Rabel's suggestion concerning an "internship or work/study program" as a part of the placement of students, which was one of his suggestions for providing a stimulating program. Although colleges and universities often provide for internship, co-op, or work/study opportunities through their placement centers, the opportunity to focus directly on the professional positions in business creates interest and connectivity networks that are impossible when an internship program extends to the larger university. We examine the internship programs on three campuses, comparing their history, current practices, and the issues related to such a significant undertaking.

The ideas generated, and procedures documented in this study will provide ideas and implementation procedures to those professors who wish to extend their own current endeavors to connect their students to the industry through development of or extension of their own internship programs. 


\section{References}

1. Boose, Mary Ann, and Ed Pleasants, "Best Practices in Collegiate Education: Undergraduate Risk Management and Insurance", Presentation at the American Risk and Insurance Association meeting, August 2001.

2. Dorfman, Mark S., "Insurance in the Undergraduate Curriculum", Journal of Risk and Insurance, 1990.

3. Eldridge, CPCU, CLU, Terry McConnell, CPCU, and Lois Smith, CPCU, "Insurance Education: A Critical Examination of Collegiate Insurance Majors and Insurance Company Recruitment Practices", Chapter Research Project, Presque Isle CPCU Chapter, May 30, 1991.

4. $\quad$ England, Robert Stowe, “At Risk: University Insurance Education”, Professional Agent, June 1990.

5. Ferguson, William L., Mark S. Dorfman, Beverly J. Frickel, and Tamela D. Ferguson, "Risk Management and Insurance Education at the Millennium", The Journal of Insurance Issues, Fall 2000.

6. Gardner, Lisa, and Joan Schmit, "Collegiate Risk Management and Insurance Education", Journal of Risk and Insurance, 1995.

7. Gardner, Lisa, and Joan Schmit, "Student Internships Develop Jobs and Talent", Best's Review (Property/Casualty Edition), 1997.

8. Gault, Jack, John Redington, and Tammy Schlager, "Undergraduate Business Internships and Career Success: Are they related?”, Journal of Marketing Education, April 2000.

9. Gustavson, Sandra G., "Crisis on the Campus", Best's Review, Property Casualty Edition, January, 1991.

10. Hite, Robert E., and Joseph A. Bellizzi, "Student Expectations With Regard to College Internship Programs", Journal of Marketing Education, Fall 1986.

11. Kwon, W. Jean, "Collegiate Insurance and Actuarial Science Education in Asia", presentation at American Risk and Insurance Association, November 1999.

12. Martz, William Benjamin, Jr., "A Three-way Partnership for Learning: On-Campus Electronic Internships", T.H.E. Journal, December 1999.

13. Rabel, William, "A Manual on How to Manage an Effective Collegiate Program in Risk Management and Insurance", Life Office Management Association, 1992.

14. Skipper, Harold D., Jr., "Risk Management and Insurance Education: Will We Miss the Boat?", Journal of Risk and Insurance, 1994. 


\section{Appendix A \\ 2003 SUMMER INTERNSHIP \\ APPLICATION}

Please type or print in ink. Attach six copies of your resume with paper clip to this application. Resumes will be sent to sponsoring organizations. Your resume should include a list of the relevant courses completed and those in progress this semester. It should also indicate your GPA (overall, or in business classes). Return completed materials to the Program Office, School of Business, Room 922 by January 18, 2003. Thank you.

Name:

\begin{tabular}{lll}
\hline First & MI & Last
\end{tabular}

Campus Address: Student ID:

Permanent Address:

Campus Telephone: ) Permanent Telephone: )

Preferred e-mail address:

Major(s): Minor(s): Anticipated date of graduation:

University Cumulative GPA: GPA in Business courses: Major GPA:

BUSINESS courses completed to date:

BUSINESS courses in progress (Spring 2003):

If you have any of the following preferences, please indicate them.

geographical location: specific company:

industry functional areas:

The above information and that on my resume is correct. I understand that I represent the university and the Program as I interview for and work at any internship arranged through the Program. I will enroll in INS439 and understand that a paper is required for completion of credit in the course. Further, I understand that any internship that is arranged through the program requires weekly submission of daily \& weekly reports. I also understand that submission of this application does not guarantee an internship.

Date: Signature:

DEADLINE FOR RECEIPT OF APPLICATION: JANUARY 18, 2003. 


\section{Appendix B \\ SPONSORING ORGANIZATION FORM}

\section{Summer Insurance Internship}

RMI Program

Please complete this form and return to (name and address for the appropriate staff member or professor in the program). Thank you.

Name of Sponsoring Organization:

Contact Person For Internship At Sponsoring Organization:

Name:

Title:

Address:

Telephone: E-mail

Our organization will sponsor: One Two student interns for summer 2003.

Areas or departments where student(s) would likely be assigned:

Do you have any requirements for these intern positions ("college sophomore, etc.") ?

Do you have any preferences for these intern positions ("knows word processing") ?

Anticipated Wage/Hour: __ $\$ 10 \_$_ $\$ 12$ Other

Our organization will not sponsor an intern for 2003, but we suggest you contact:

Name:

Date:

Position: Telephone: 


\section{Appendix C \\ INTERN EVALUATION FORM}

BUSINESS PROGRAM

(contact information goes here)

Intern Name

Date of Evaluation

Company

Departments/Divisions in which intern worked:

Internship Period

\section{Major Responsibilities and Assignments of Intern}

II. Accomplishments

III. Training In-house or outside in which intern has participated:

IV. Performance Rating: Check the rating that most closely describes the intern's performance.

4 - excellent 3 - good 2 - adequate 1 - inadequate

Work Quality: The reliability, accuracy, and neatness of work produced.

4() 3() 2() 1() Comments:

Work Quantity: The amount or volume of work produced/completed.

4 () 3() 2() 1() Comments:

Judgment: The ability to make well-reasoned, sound decisions that affect work performance.

4() 3() 2() 1() Comments:

Initiative: The combination of job interest, dedication, and willingness to extend oneself to complete assigned tasks.
4()$\quad 3() \quad 2() \quad 1()$
Comments:

Teamwork: The working relationship established with fellow employees in the working environment.

4() 3() 2() 1() Comments:

Dependability: The reliance that can be placed on an employee to persevere and carry through to completion any task assigned. This also applies to attendance and punctuality. 4 () $3($ ) 2() 1 () Comments:

Attitude: Demeanor; propensity and willingness to learn new things; openness to new ideas. 4() 3() 2() 1() Comments:

Written Skills

4 () 3() 2() 1() Comments:

Verbal Skills

4() $3($ ) $2($ () 1 () Comments:

Quantitative Skills

4() 3() 2() 1() Comments: 


\section{Computer Skills}

4() 3() 2() 1() Comments:

Interpersonal Skills

4() 3() 2() 1() Comments:

V. Overall Performance Rating (check one)
4()$\quad 3() \quad 2()$
Comments:

Suggestions for future internships: 


\section{Appendix D}

Student

Company

Co. Phone

Co. Fax

E-mail

\section{Daily Record}

(Record on this form daily and use it to complete the weekly report).

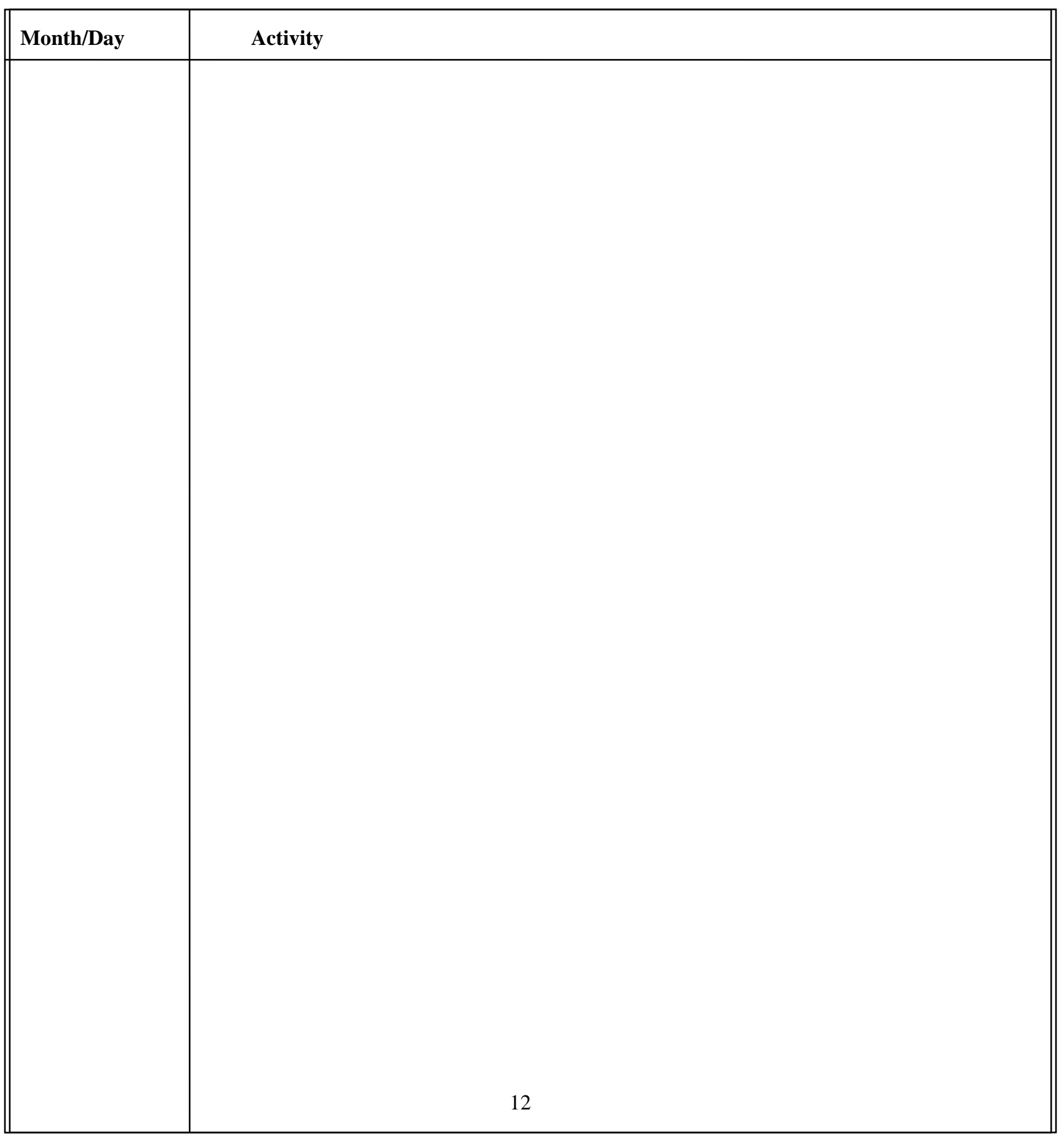




$\begin{array}{ll} & \text { Appendix E } \\ & \text { Student } \\ & \text { Company } \\ & \text { Co. Phone } \\ & \text { Co. Fax } \\ & \text { E-mail } \\ & \\ & \text { Week of }\end{array}$

(Use the information from your Daily Record to complete this form at the end of the week).

A. What experiences have been most valuable or most interesting during the past week?

(List two or three)

B. How do these experiences relate to/extend classroom knowledge?

C. Have any of the activities influenced your thinking as related to your career? 


\section{Notes}

